\title{
Supporting local governance and local economic development - some experiences from Swaziland
}

\section{Commonwealth Journal of Local Governance}

Issue 18: December 2015

http://epress.lib.uts.edu.au/ojs/index.php/cjlg

\section{Terry Parker}

Commonwealth Local Government Forum

Former Regional Adviser CLGF Southern Africa Programme

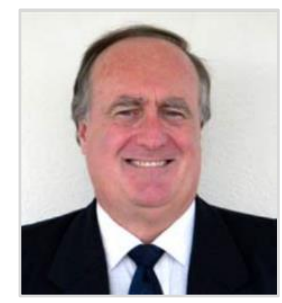

\begin{abstract}
In the December 2012 issue of this Journal, Lucy Slack and Susan Rhodes (2012) of the Commonwealth Local Government Forum (CLGF) introduced a new CLGF programme focussing on improving governance and service delivery at local level in selected Commonwealth countries in Southern and West Africa and South Asia (CLGF no date; CLGF 2015). The initiative is in the third year of its four-year lifespan and it is opportune to examine progress made so far towards achieving the development aims sought by the programme funders, CLGF and partners in 2012. This contribution will explore the operationalisation of the programme to date through a snapshot of implementation in one country under the Southern Africa component of the programme, Swaziland. It will briefly describe how the project emerged, what it intends to achieve, examine progress to date and conclude with some observations around what has been learned so far. The paper draws on the author's work as Regional Adviser for the CLGF Southern Africa Programme based in Pretoria and project documentation (see Acknowledgements).
\end{abstract}

\section{Background}

The CLGF programme is funded by the UK Department for International Development (UK aid) and primarily focusses on a range of pilot Local Economic Development (LED) related initiatives at regional, national and local levels. Running from 2012 to 2016 the initiative is supporting CLGF's work to improve local government service delivery to reduce poverty and contribute to international development goals. The approach underpinning the programme is that local governance is placed at the centre of local development.

(C) 2015 Terry Parker. This is an Open Access article distributed under the terms of the Creative Commons Attribution 4.0 Unported (CC BY 4.0) License (https://creativecommons.org/licenses/by/4.0/), allowing third parties to copy and redistribute the material in any medium or format and to remix, transform, and build upon the material for any purpose, even commercially, provided the original work is properly cited and states its license.

Citation: Commonwealth Journal of Local Governance 2015, 18: 4839, - http://dx.doi.org/10.5130/cjlg.v0i18.4839 
The Southern Africa component addresses two of the four outcomes expected from the UK funding:

- Improved skills, knowledge and organisational capacity for local authorities to deliver LED services through successful implementation of CLGF funded projects with a good spread across countries and regions.

- Improved national policy making and supporting frameworks for effective local government service delivery.

Implementation began with an inception and information sharing workshop for the twelve participating Southern African countries ${ }^{1}$ that was held in Pretoria, South Africa, in February 2013. The overall programme design called for the selection of four pilot countries to implement the national and local level activities. Interested countries were invited to submit concept notes on projects promoting LED for consideration as pilots and based on the submissions received: Botswana, South Africa and Zambia together with Swaziland, the subject of this commentary, were chosen.

\section{The Kingdom of Swaziland}

With an estimated population of 1.4 million, Swaziland is landlocked, bordering South Africa and Mozambique (CLGF 2013b). The CLGF project takes cognisance of the challenges Swaziland faces in relation to chronic unemployment of around $40 \%$ and high levels of poverty, ${ }^{2}$ exacerbated by an estimated $26 \%$ of adults living with HIV and AIDS. The economy has been significantly impacted by the global economic downturn which saw a pronounced decline in export oriented manufacturing coupled with uncertainties of revenues from the Southern Africa Customs Union and the loss of status under the United States African Growth and Opportunities Act (AGOA).

The constitution of the Kingdom of Swaziland (Government of Swaziland 2005), which came into effect on 8 February 2006, also impacts significantly on the project's thinking. It reflects the desire to ensure efficient management and national development, as well as to improve living conditions and wellbeing of the people, be they residing in the urban centres or the traditionally administered areas, whilst still preserving the values and systems of a traditional society.

The Constitution provides for the establishment of a single country-wide system of local government based on the tinkhundla $a^{3}$ political philosophy and system of government. The purpose of this provision is to bring government closer to the people so that those at sub-national or local community level progressively take control of their own affairs.

\footnotetext{
${ }^{1}$ Angola, Botswana, Lesotho, Malawi, Mauritius, Mozambique, Namibia, South Africa, Swaziland, Tanzania, Zambia and Zimbabwe.

2 Per capita income is around US\$3,000pa but as is common in many African countries, income is highly skewed with $69 \%$ of people living below the poverty line.

3 Traditional system of devolution of state power to grassroots administrative and developmental units, comprising several chieftaincies, within regions.
} 
Additionally, a national Decentralisation Policy was adopted in August 2006 to:

provide an enabling environment for promoting and enhancing sustainable and local participatory local and national economic, political and social development within a decentralized governance framework and is based on the fundamental principles of subsidiarity, empowerment, responsibility, partnership, connectivity, accountability, transparency, equity, inclusiveness, responsiveness, efficiency, effectiveness, participation, consensus, democratic representation and respect for the rule of law (Government of Swaziland 2006, p.10).

To formally operationalise both the Constitutional provisions as applying to local government and the Decentralisation Policy, a draft Tinkhundla and Regional Administration Bill, was prepared and is currently being consulted.

The Swaziland government had also been active in pro-poor approaches, as evidenced by the Poverty Reduction Strategy and Action Programmes (also known as Yingcamu) which emphasises the importance of decentralised institutional frameworks through devolved local government structures.

\section{Project rationale and scope}

The Swaziland component was designed via a collaborative and participatory process involving the Swaziland Ministry of Housing and Urban Development (MHUD), Ministry of Tinkhundla Administration and Development (MTAD), Swaziland Local Government Association (SWALGA), Local Authority Managers Association of Swaziland (LAMAS), the Municipal Councils of Mbabane, Manzini and Matsapha, and CLGF. The design process began by undertaking capacity assessments in each of the three pilot municipalities, with the purpose of identifying service delivery gaps the project may address and provide baseline information. The data gathered was used to prepare a report (CLGF 2013a) which together with the original project concept note (Government of Swaziland 2014) submitted by Swaziland partners provided the background for a workshop where the final project design was developed and eventually agreed by all stakeholders.

The strategic thrusts of the project are around:

- governance and an enabling policy environment for LED - including improved recognition of local government in national development, effective inter-governmental relationships and national policy and clear local authority mandates.

- institutionalising LED at the local level - encompassing capacity to plan and embed the LED approach into service delivery, managing stakeholder engagement and empowerment, advocacy and communication, knowledge management and issues around financing LED projects.

- capacity building - strengthening individual capacities of elected leaders, ministry and municipal officials and key community stakeholders particularly in facilitation of the LED approach to service delivery. 
- programmatic LED interventions - including developing local authority LED strategies, design of LED undertakings and building on past and existing initiatives.

The project includes national level activities related to the recognition of local government and projects in three selected pilot local authorities located within a recognised development corridor:

- Municipal Council of Mbabane - the capital city and administrative centre;

- Municipal Council of Manzini - the commercial hub and geographically central;

- Matsapha Town Council - the core industrial area.

The aim is to help enhance the capacities of these councils to effectively deliver LED-focussed services. The project design incorporates a range of activities at the strategic and policy level, both nationally and at local authority level, combined with catalytic initiatives within the pilot local authorities.

In developing the CLGF project, it was apparent that stronger, better empowered and more sustainable institutions at local level would be required to meet future expectations. An informed and engaged constituency, well capacitated leadership, skilled management and effective systems were clearly essential for success.

It was also noted that the principles of developmental local government, as expounded by the Kampala Declaration, ${ }^{4}$ in fact resonate well with the objectives of the Swaziland Constitution and Decentralisation Policy and would form a solid foundation for the project. In particular:

- local governance that is inclusive, transparent and participatory;

- innovative sustainable, people-sensitive local economic growth and social development;

- integrated and coordinated developmental activities of public and non-state actors; and

- leadership and building of social capital.

\section{Project objectives and progress towards their achievement}

The overall goal of the Swaziland project is to enhance the role of local government as a key agent in local economic empowerment and national development. Specifically, the following objectives are central to the programme.

\section{Local government institutions are recognised as integral to national development}

Local government's key role in national development has been clearly recognised in the Constitution and national Decentralisation Policy. The project aims to contribute to achieving the aims of these instruments and in doing so enhance the institutional legitimacy of local government in Swaziland.

\footnotetext{
${ }^{4}$ Kampala Declaration on Developmental Local Government adopted at the Commonwealth Local Government Conference held in Kampala, Uganda in May 2013 and subsequently endorsed by Commonwealth Heads of Government in Colombo, Sri Lanka, in November 2013.
} 
Recognition and application of the concept of developmental local government was identified as the most appropriate mechanism to add value in this area.

Within this objective are a variety of activities based on advocacy and sensitising local elected leadership on the concept, purposes and potential value of developmental local government together with strengthening lobbying and advocacy capacity of the key players - SWALGA and LAMAS - to effectively promote and embed the role of local government in national development. A national symposium on developmental local government will bring this action together. This high-level event will reinforce the advocacy efforts and focus on policy and issues related to the value adding potential of adopting a developmental local government approach and draw attention to the potential contributions of local government to nation building. It will involve key political decision makers with a view to building buy-in and and adopting concrete and realistic ways on how to better embed local government in the national governance landscape.

Progress on implementing the agreed activities under this first project objective has been slow. This is indicative of the complexity surrounding the issues involved and the need to take time to sensitise and bring on board key stakeholders and build sympathetic understanding by political decisions makers. As such, a broader time frame has been allocated for the required tasks. Nonetheless significant progress has been made in harnessing support of the MHUD and MTAD at both political and operational levels.

In achieving the expected results, the importance of a stable and well-functioning local government association is essential. SWALGA, supported technically by LAMAS, was tasked to take the lead in driving the necessary actions in this outcome area, and at varying levels in the other three. SWALGA is undergoing a strategic transformation process and this project is also seen as a catalyst to SWALGA identifying its place in promoting local governance in Swaziland through tangible actions.

\section{An enabling national policy and legislative framework is in place to facilitate LED}

A guiding framework for LED was considered essential for:

- defining LED in the context of local government;

- ensuring linkages with the Constitution and Decentralisation Policy;

- coordination and focus of efforts with national LED related agencies and actors;

- making sure urban/rural dimensions and a pro-poor approach are included;

- capacity and information sharing information; and

- monitoring and evaluation. 
Proposed initial actions include developing and gaining formal approval of an institutional framework under which LED can be facilitated, undertaking research on regional and international good practices and extensive consultations.

It was agreed in the project design that LED related project activities, particularly the orientation on LED in the three pilot municipalities would proceed and learning from these will inform the development of the national framework. It was, however, decided recently that the time is now right to begin preparing the policy framework and expert technical assistance has been engaged to facilitate this process.

Stakeholders also recognised the potential opportunities in exploring collaboration with the private sector at local level via public/private partnerships (PPP). Development of a PPP policy and coordination structure for local authorities to complement the national PPP framework was included in the project outputs, together with preparation of a guideline on how to identify and package potential PPP projects based on revealed opportunities in the three pilot municipalities.

This activity is scheduled for the final stages of the project given the need to fully investigate the application of a PPP approach to local government as this a complex area beset with risks and requiring careful analysis and planning. Initial research and discussions are however underway, drawing extensively on international and regional experiences with PPPs.

\section{Poverty reduction, economic empowerment and sustainable community livelihoods achieved through improved planning, management and implementation of LED initiatives}

This outcome is the main focus area of the project and relates to a range of activities implemented at the local authority/grassroots level.

The initial output considered in the project design as underpinning all activities was the development of individual capacities of local authority elected leaders, officials and key stakeholders to facilitate inclusive service delivery and LED. Orientation programmes were conducted in each of the three pilot municipalities, facilitated by a prominent regional specialist in LED. The programmes were successfully carried out in July/August 2014, resulting in the training of 100 councillors, senior council officials, government ministry and statutory agencies officials and business association representatives on LED and the development and implementation of LED strategies.

The orientation was immediately followed by a one day Business Indaba $a^{5}$ in each municipality where the opportunity was taken by the councils to engage with their business community in dialogue and sensitisation on LED and obtain inputs on LED in the local context to inform the LED strategies. A

\footnotetext{
${ }^{5}$ An important gathering or meeting.
} 
total of 474 business people attended these events; however Matsapha Municipality conducted two separate Indabas, one for the formal businesses and another for informal traders.

The informal traders event in Matsapha attracted some 342 participants and resulted in a range of recommendations aimed at assisting the more marginalised private sector participants, including the establishment of an Informal Traders Association. These consultative and participatory events contributed significantly to enhancing goodwill between the council and business community, something that had not always been present. Manzini Municipality subsequently held an equally successful workshop for 120 informal traders in November which also served to strengthen the relationship between the formal and informal sectors.

The next step in the project plan was to prepare LED strategies for Manzini and Matsapha Municipalities. ${ }^{6}$ This activity included SWOT analysis, an environmental scan, baseline survey and analysis of the local economy, and agreeing the strategic focus. The LED strategies have been drafted and are currently awaiting consideration and adoption by the councils.

It was however discovered early in the implementation of this activity that collecting accurate economic data in a cost-effective and efficient way was not easy. After investigation of alternative modalities it was agreed that the councils carry out the data collection themselves, which it was proved they were well capable of doing, in collaboration with the University of Swaziland which provided specialist technical support to the analysis of the data and quality control of the processes.

A number of activities to localise the national poverty reduction strategy are also underway in parallel with, and aimed at, informing the strategy development. Over the life of the project these include:

- a national urban agriculture promotion strategy;

- a public transport network and operation management strategy;

- local outsourcing and engaging community based labour/local contractors for local maintenance tasks, including skills training;

- labour pooling and income generation projects for unemployed youth;

- $\quad$ waste management strategy;

- waste collection and recycling programme in peri-urban areas;

- training for market traders and demonstration projects.

Implementation to date has been focussed primarily on the waste management and market trader activities. Matsapha Municipality has completed a waste management strategy which involved sensitising stakeholders and successfully enlisting the support of relevant government agencies and

\footnotetext{
${ }^{6}$ Mbabane Municipality had already prepared a five year LED strategy in 2011, but would be looking to review this in due course.
} 
the private sector (specifically those companies involved in waste management) via a series of workshops and consultations. Recycling is a key component of the strategy and so far 30 informal reclaimers have been formally registered and trained in creating value added products from waste, hence opportunities for income generation. As a result of the project, 18 people are now employed.

The waste collection activity in peri-urban areas around Matsapha addresses serious waste management issues and also creates economic opportunities through recycling and levies on households. This project has been supported by the Regional Administration and traditional authorities. Again this demonstrates how urban and rural authorities can effectively work together.

However in implementing both these initiatives Matsapha Municipality found that the community consultation processes were lengthy due to the complexity of the political processes and the need to navigate protocols within the traditional system. In addition, the peri-urban communities were sceptical due to past failed projects and required a deal of reassurance by the council on the practical benefits and sustainability of the projects. Nonetheless, the strategies applied were successful and as a result, 180 people have so far participated in the multi-stakeholder clean-up campaign.

Manzini Municipality operates a 'Thursday Market' which provides trading opportunities for people from Manzini and also from rural and smaller urban areas from all over Swaziland. The CLGF project is supporting the council to provide training and demonstration projects. Training is being undertaken via a Training of Trainers modality in partnership with private sector entrepreneurship development service providers. So far 200 trainers, who are mostly market vendors themselves, have been trained and are imparting knowledge to their peers. As a result of the project, 20 informal sector traders were able to exhibit their goods and traded at the Swaziland International Trade Fair held in Manzini from 29th of August to 7th September 2015.

Additionally, Manzini Municipality has developed guidelines on local outsourcing and engaged community-based labour for local maintenance. The idea was piloted in two sites and has resulted in the employment of 25 people.

Another cross-cutting output is around community and stakeholder engagement and empowerment on LED. This involves developing LED advocacy and communications strategies, production of IEC materials, capacity building of identified community structures on LED, facilitating structured and regular community consultations around LED, particularly with the business community and marginalised groups.

The final initiative under this objective is being undertaken by Mbabane Municipality and is aimed at instilling understanding of the role played by the environment in sustainable local economic development, whilst also providing an opportunity to generate income by local residents. It builds on a twinning partnership between Mbabane Municipality and Salo Municipality in Finland. This output 
involves a mix of capacity building and demonstration projects around sustainable environmental management. In particular, waste prevention and minimisation, reuse and recycling, including composting and production of commercial products, sustainable sanitation and climate smart organic gardens.

This activity has also proved to be a success with 836 community people so far trained in sustainable environmental management and production of commercial products from recyclable waste. Additionally, 743 climate smart-gardens have been established, providing opportunities for food security in the urban areas. Remarkably, the targets for each of these activities in the project design were 200. Mbabane communities have also produced 2,438 kg of compost, against the planned 400kg, most of which was used in the climate gardens while some is being sold for $\$ 7$ per $\mathrm{kg}$.

Monitoring of implementation at a broad community level, however, became a challenge for the council. This was overcome by part-time employment of university students to inspect progress and ensure resources were effectively used, again creating employment.

\section{Efficient and effective project management}

A Project Steering Committee (PSC) comprising representatives of all the partners ${ }^{7}$ was established at the commencement of the project to provide strategic guidance and oversight, prepare annual workplans, approve fund disbursements, ensure contractual and reporting requirements are met, project protocols are followed and promotion of the project. The PSC has met religiously at least quarterly, with full attendance of members at most meetings, and has delivered effectively on its mandate. In accordance with CLGF preferred approach, planning and implementation of projects is as far as practicable locally driven. The CLGF Southern Africa Programme Office based in Pretoria, however, is responsible for overall management of the Southern African component of the programme. Responsibility for local project implementation rests with each respective Municipal Council. The project design specifies that in-country project coordination is provided by the SWALGA Director, who reports on project execution to the Regional Programme Manager.

\section{Risks and risk management}

Consistent with projects of this nature, there are some inherent risks which might impact on successful implementation. However, to a large extent these flow from the very factors that make the project necessary. Some of the risk management strategies adopted include:

- regular communication between partners and ensuring alignment with national and sectoral strategies to maintain political and administrative support;

\footnotetext{
${ }^{7}$ The PSC comprises Ministry of Housing and Urban Development (Chair); Ministry of Tinkhundla Administration and Development; Chief Executive Officers and LED Officers of Mbabane, Manzini and Matsapha, Swaziland Local Government Association and CLGF Southern Africa.
} 
- adopting a flexible management approach and maintaining a strong partnership and working relationships to sustain buy-in;

- realistically managing expectations and maintaining a technical focus;

- taking cognisance of absorptive capacity of implementing institutions when setting targets;

- ensuring accurate budgeting and remaining within allocations;

- making consistent visible achievements to retain community participation;

- a focus on quality of inputs and outputs through regular internal evaluation;

- effective two-way internal and external communication with all stakeholders to ensure understanding of project actions.

\section{Monitoring and evaluation}

As noted, quality of outputs will determine the achievement of project outcomes and impact. The programme design provided for gathering baseline information at the beginning of the project, in particular via service delivery satisfaction surveys. Although a comprehensive template and methodology for the surveys was developed, several challenges were encountered in how to objectively and cost-effectively administer the surveys. Private services providers were found to be disproportionately expensive and it was then decided to integrate the satisfaction surveys with the business environment surveys that are a component of developing LED strategies for Manzini and Matsapha. Fortunately Mbabane Municipality had recently carried out a customer satisfaction survey which can be applied. Other quantitative indicators based on numbers have been included in the overall programme together with country specific project designs which are monitored through relevant data collection. Although somewhat early to actively consider the outcomes and impact of the Swaziland project, some internal qualitative assessments such as pre and post training evaluations have been carried out (these have been positive). However more work remains to be done on impact evaluation.

\section{Overview and observations}

The question often posed when stepping back and looking at a project such as this is - so what? Here are a few reflections on what has happened so far and what has been learned. Although realistically only a little over two years into implementation, it is becoming apparent that this project is meaningful and has potential to facilitate positive change (CLGF 2014). The evolution of local government in Swaziland has provided an appropriate foundation and entry point for the CLGF project, which was welcomed by the Government of Swaziland, the local government association and the selected pilot local authorities. Opportunities to assist with the development of a new approach to local government and its systems were clearly at hand, which reinforces the potential value and appropriateness of this project. 
CLGF is distinguished by its singular focus on local government, the 'trusted partner' approach and working in collaboration with implementing partners as equals. As with most CLGF projects, activities are agreed with, and implemented by, relevant in-country partner agencies. Although the success or failure of projects rests on this basis and implementation invariably takes longer than other more direct execution modalities, evidence from this project, such as the quality of outputs so far, reveals that the national execution method provides greater potential for sustainable outcomes. However challenges around maintaining solid partnerships need to be monitored, with a 'Plan B' always at hand to manage any emerging fragilities and ensure implementation is not delayed.

At this stage of implementation, it has been noted that activities with a social component, such as the Mbabane environmental sustainability, Manzini market and Matsapha solid waste undertakings, have been implemented more expeditiously and effectively. The focus on social cohesion as a precondition to effective LED promotion, and that LED activities can also reinforce social cohesion, became very clear as these activities were implemented. The project also highlights the multidimensional nature and complexity of development and poverty. Successful poverty-related interventions need to collectively target different angles of development such as social, economic and capacity development.

Equally, activities implemented at local government management/administrative level (Objective 3 primarily) have so far been implemented more successfully than those with a more political focus, such as those in Objectives 1 and 2. The complexities at political level, particularly around decentralisation, need to be factored in and will likely cause delays; however it is essential to obtain the necessary high-level political buy-in before proceeding. The project should harness the strengths of this complexity to build a solid political foundation for enhancing the key role of local government in national development. Clearly local participation, partnerships and relationships remain the heart of this endeavour. Making sense of, valuing and harnessing the knowledge of the 'doers' is essential. To achieve this it is apparent from experiences so far that all partners should adopt an implementation attitude of flexibility and shared curiosity rather than individual certainty.

There have been several instances, such as longer than anticipated time taken to align national and local government reporting protocols with CLGF requirements, where the project may be 'building the ship while sailing along'. It is not possible to foresee all variables in a project design and it was considered important to spend time to establish the systems that will remain in place for the entire project. The importance of having a dedicated LED official in each pilot municipality became apparent as the project began the implementation phase. Apart from giving a tangible emphasis to the critical area of LED at local government level, the LED officer is a logical focal point for the project. Mbabane Municipality had already established a position of LED officer and Manzini and Matsapha Municipalities made similar appointments shortly after the project commenced. 
On the subject of monitoring and evaluation, the project design contains quantitative targets which can be monitored to a reasonable extent, but evaluating impact is a different story. Projects which aim for socio-economic change and contain complex, intangible outcomes require a different approach to evaluation. It may be necessary to look beyond measures such as service delivery satisfaction surveys that are subjective and imperilled by a range of variables and consider complementing the surveys with other participation and/or theory techniques to deliver a more balanced formative and summative evaluation. Some stakeholders were concerned at the adopted 'pilot' local authority approach. People generally do not like pilot projects, they are not politically appetising especially if their organisation is not a part, preferring an all-inclusive arrangement. Due to budget constraints and the need for experimentation before expansion, this was not possible, however, efforts to involve other local authorities in the project were made, such as inclusion in the LED orientations, councillor training and symposia. Learning from the pilots will also be disseminated and hopefully additional resources mobilised to roll out to all local authorities in the country.

The Swaziland project highlights how the bottom-up and top-down approaches to development can be used in one endeavour - how local government enables this and how the LED approach becomes the means to translate national policy at the local level while at the same time responding to local needs. The role of local government in development can be clearly defined in all levels of this process, for example how the project seeks to localise the Poverty Reduction Strategy and the PPP policy in parallel with developing LED strategies. One of the strengths of the CLGF project revealed during the first two years is the robust commitment from partners and stakeholders, and their positive and collaborative approach to addressing the challenges that have emerged. If this continues the future of the project is bright and leads to expectations of enhanced and sustainable achievements in the forthcoming year and beyond.

\section{Acknowledgement}

From September 2012 to end December 2014 the author was the Regional Adviser for the CLGF Southern Africa Programme based in Pretoria. As part of his work for CLGF, he was responsible for managing the Swaziland project. The contextual information and findings in the article were based on the overall programme document, the project scoping and design and implementation processes, and current data provided by the Swaziland partners and the CLGF Southern Africa Regional Programme Manager. The observations and conclusions in this paper are those of the author.

The author is extremely grateful to CLGF Southern Africa Regional Programme Manager, Nyasha Simbanegavi, for comments on and inputs to this article.

The contributions of the Chief Executive Officers and LED Officers of Mbabane, Manzini and Matsapha Municipalities, together with senior officials of the Ministries of Housing and Urban 
Development, Ministry of Tinkhundla Administration and Development and the Swaziland Local

Government Association in provision of data for this article, together with their passionate commitment to the project, are also acknowledged with appreciation.

\section{References}

Commonwealth Local Government Forum. (CLGF) (2013a) Southern Africa regional programme Swaziland pilot project. Project Design Document. Unpublished.

Commonwealth Local Government Forum. (CLGF) (2013b) Swaziland country profile. Available at: www.clgf.org.uk/swaziland [Accessed May 2015].

Commonwealth Local Government Forum. (CLGF) (2014) Swaziland project progress report April to September. Unpublished.

Commonwealth Local Government Forum. (CLGF) (2015) Southern Africa programme. Available at: www.clgf.org.uk/southern-africa-programmes [Accessed May 2015].

Commonwealth Local Government Forum. CLGF) (no date) Southern Africa programme flyer. Available at: www.clgf.org.uk/userfiles/1/file/CLGF_Southern_African_Regional_Programme_flyer.pdf

Government of Swaziland. (2005) The constitution of the Kingdom of Swaziland Act (Act No 001).

Government of Swaziland. (2006) Decentralization policy. Swaziland Government, August 2006.

Government of Swaziland. (2014) - Ministry of Housing and Urban Development, Swaziland Ministry of Tinkhundla Development and Administration, Swaziland Local Government Association. Project Concept Note. Unpublished.

Slack, L. and Rhodes, S. (2012) New CLGF four-year grant to help local government service delivery and boost CLGF research capacity. Commonwealth Journal of Local Governance, 11, 136-138. Available at: https://epress.lib.uts.edu.au/journals/index.php/cjlg/article/view/3080.

doi: http://dx.doi.org/10.5130/cjlg.v0i0.3080 